\title{
BASAL CELL CARCINOMA IN MIDDLE EAR: A CASE REPORT
}

\section{T. Shankar' ${ }^{1}$, S. Ramakrishna², E. Yugandhar ${ }^{3}$, Juveria Majeed ${ }^{4}$}

\section{HOW TO CITE THIS ARTICLE:}

T. Shankar, S. Ramakrishna, E. Yugandhar, Juveria Majeed. "Basal Cell Carcinoma in Middle Ear: A Case Report". Journal of Evolution of Medical and Dental Sciences 2015; Vol. 4, Issue 17, February 26; Page: 2993-2999, DOI: $10.14260 /$ jemds/2015/433

ABSTRACT: Basal cell carcinoma is a very common skin cancer, it is much more common in fair skinned individuals with a family history of Basal cell carcinoma and increases closure to the equator or at higher attitude, this tumor is a extremely rarely found in the middle ear, accounts for $45 \%$ of all auricular carcinomas and is more common than squamous cell carcinoma, it is most frequently found in patient between 40 and 60 years of age, sunlight exposure is the most common modifiable risk factor, we are here presenting a case of Basal cell carcinoma in middle ear presented with ear discharge and polyp in external auditory canal and middle ear, treated with radiotherapy

KEYWORDS: Basal cell carcinoma, Radiation, Ultraviolet rays, Middle ear, Melanoma.

INTRODUCTION: The ear: there are three parts in the ear 1. Outer ear, 2. Middle ear. 3. Inner ear. Middle ear (Figure No.1): The middle ear is a small cavity which contains 3 small bones (ossicles), these pass on the vibrations from the external ear to inner ear, another important part of the ear, is the temporal bone surrounds and protects the ear.

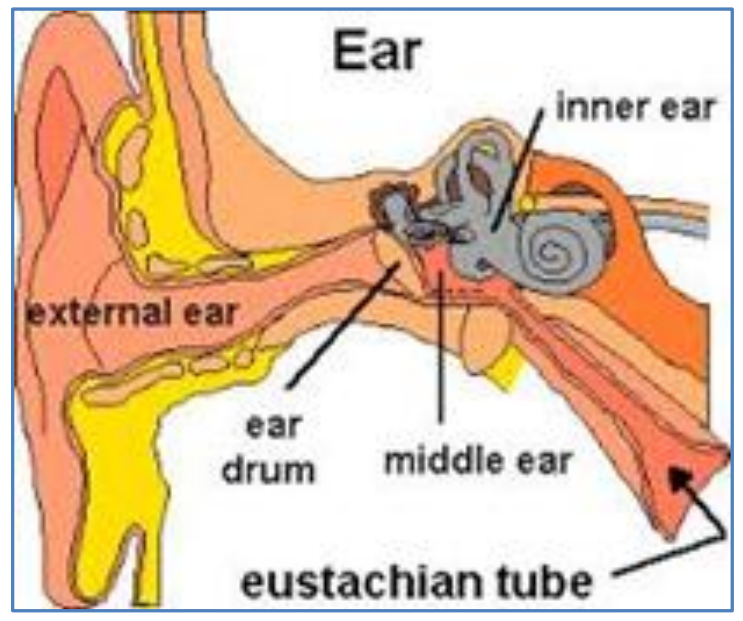

Fig. No. 1: Middle Ear

The causes of cancer in middle ear is unknown, the symptoms of cancer of the ear depends on where the tumor is within the ear, the most common symptom is a discharge from the ear which may be blood stained, otorrhea, hearing loss and earache. If the inner ear involves pain including headache, hearing loss, tinnitus and dizziness.

What is Basal Cell Carcinoma? (Figure No. 2)

Basal cell carcinoma is a locally aggressive neoplastic lesion which develops from the basal layer of the skin, it is the most common cancer in united states (1). In $80 \%$ of all cases, basal cell cancers are found on the Head and Neck. (2) 

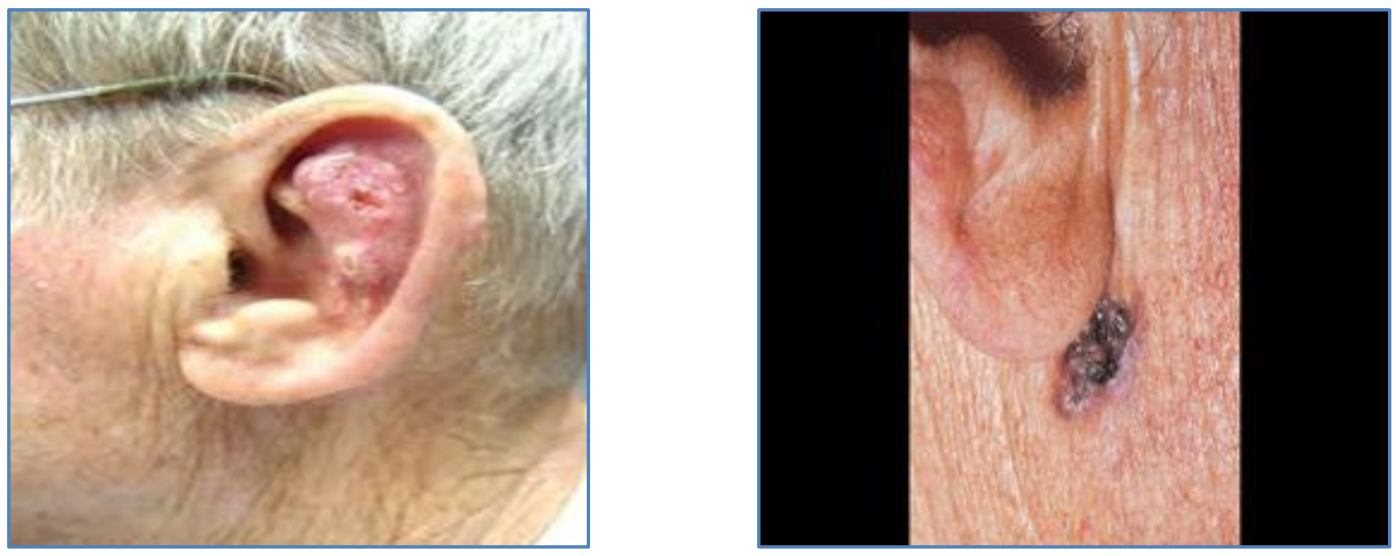

Fig. No. 2: Basal cell carcinoma photos

Basal cell carcinoma for $45 \%$ of all auricular carcinomas, it is most frequently found in patients between 40 and 60 years of age, patients with fair skin, lighter coloured hair and a tendency to sunburn, specifically Fitzpatrick skin type I, are more commonly effected, occupational exposure to ultraviolet rays has also been shown to increase risk. To diagnose basal cell carcinoma a shave biopsy (Scrapping a small piece of skin) under local anesthesia is taken for pathological study. The diagnosis should be made when the cancer is early and treatment should be started immediately to prevent the tumor from spreading.

CASE REPORT: A 45 years old female patient, came from Mahaboob nagar with complaints of decreased hearing in right ear since 02 months, blood stained ear discharge from right ear since 1 month, which is persistent not relived with medication, on examination muco-purulent discharge and pinkish proliferative polypoidal mass seen in external auditory canal, (Figure No.4), soft in consistency. No history of giddiness, headache, and facial weakness, patient was investigated.

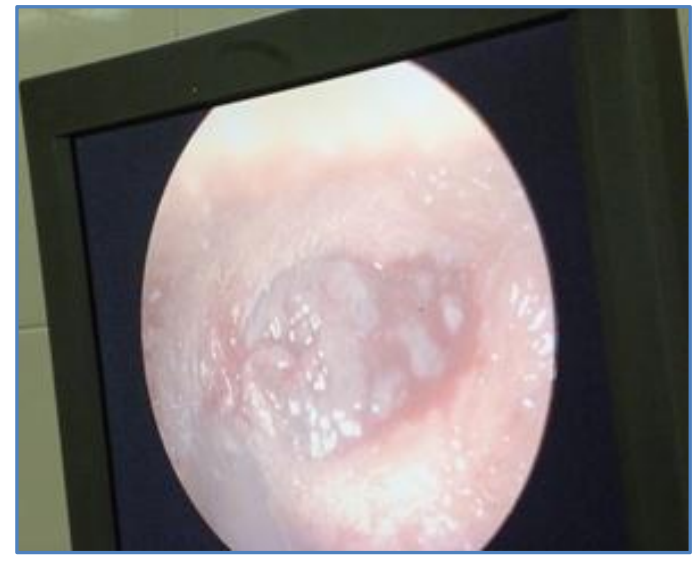

Fig. No. 3: (EUM Photo)

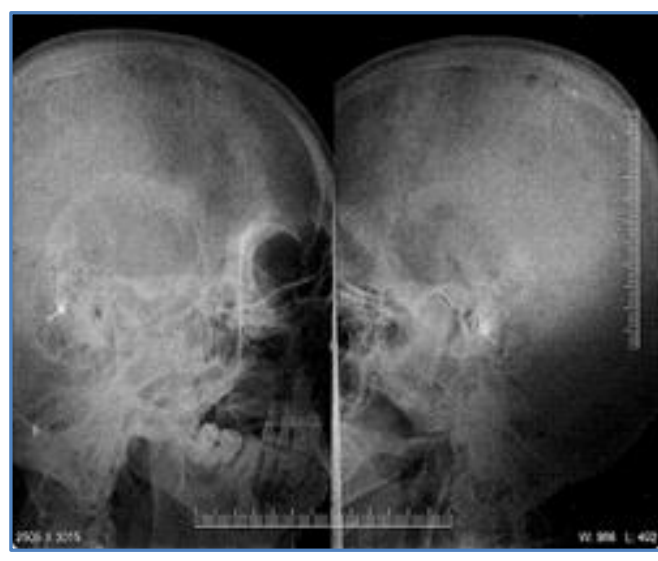

Figure No. 4: (X-Ray Mastoids)

All the investigations were with in normal limits, except (R) Mastoid sclerotic (Figure No.4). Patient posted for mastoid exploration under local anesthesia, mastoid surgery was planned thinking that the case is chronic suppurative otitis media with aural polyp. 


\section{CASE REPORT}

Through post aural approach mastoid exploration done, the granulations present in mastoid antrum and middle ear cavity with profuse bleeding, surgery could not be proceeded because of bleeding, polyp is taken and sent for HPE, wound closed in layers, mastoid dressing applied, postoperative recovery was uneventful.
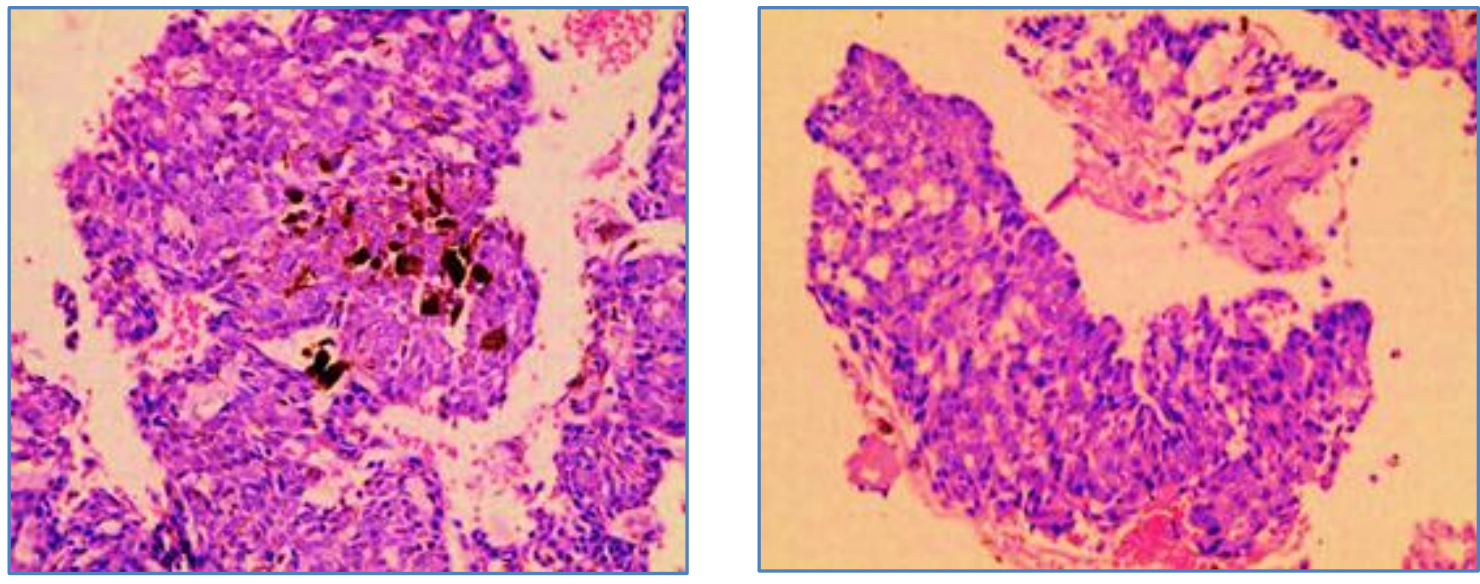

Fig. No. 5: (HPE Report)

HPE Report (Figure No.5):- Biopsy No. 1665/14.

Serial sections show small fragments of tumor tissue with histological features of Basal cell carcinoma.

As the patient refused for second surgical procedure patient was sent for radiotherapy, on follow up after irradiation patient is doing well, all the granulations disappeared in external auditory canal and middle ear cavity.

DISCUSSION: Basal cell carcinoma is the most common type of ear and temporal bone cancers, a scaly area of skin on the ear, which does not improve with the application of moisturizer, is usually the first sign. Then a pearly white bump appears which grows slowly. The bump can be painless or an ulcer might develop in the center of the bump. The ulcer later bleeds and becomes painful. These tumors can spread to inside the ear, but rarely other parts of the body. The skin on the ear (pinna) is exposed to the sun, after years of exposure, basal cell skin cancer or squamous cell cancer can develop. Temporal bone tumors are usually caused by a tumor that begins on the skin near the ear and later spreads to the bone. Fair skinned people are more susceptible to skin cancer and therefore have a greater risk of developing temporal bone cancer, chronic skin infections of the ear canal increases the risk.

\section{Basal - cell carcinomas may be divided into the following Types ( 3 \& 4):}

1. "Nodular basal -cell carcinoma" most commonly occurs on the sun-exposed areas of the head and neck.

2. "Cystic basal-cell carcinoma" is characterized by dome-shaped, blue-gray cystic nodules.

3. "Cicarticial basal -cell carcinoma" is an aggressive variant with a distinct clinical and histologic appearance. 


\section{CASE REPORT}

4. "Infiltrative basal-cell carcinoma" is an aggressive type characterized by deep infiltration.

5. "Micro nodular basal-cell carcinoma" is characterized by a micro nodular growth pattern.

6. "Superficial basal-cell carcinoma" occurs most commonly on the trunk and appears as an erythematous patch.

7. "Pigmented basal-cell carcinoma" exhibits increased melanization. About $80 \%$ of all basal cell carcinoma in Chinese are pigmented while this subtype is uncommon in white people.

8. "Rodent ulcer" is a large skin lesion of nodular basal cell carcinoma with central necrosis.

9. "Fibroepithelioma of pinkus" most commonly occurs on the lower back.

10. "Polypoid basal-cell carcinoma" is characterized by exophytic nodules (Polyp-like structures) on the head and neck.

11. "Pore-like basal cell carcinoma" resembles an enlarged pore or stellate pit.

12. "Aberrant basal-cell carcinoma" is characterized by the formation of basal-cell carcinoma in the absence of any apparent carcinogenic factor, occurring in odd sites such as the scrotum, vulva, perineum, nipple and axilla.

Basal cell carcinomas are differentiated toward the folliculosebaceous-aprocine germ, also known as the trichoblast. The differential diagnosis with trichoblastic carcinoma, a rare malignant trichoblastoma, is often difficult to make.(5) Overexposure to sun leads to the formation of thymine dimers, a form of DNA damage. While DNA repair removes most VU-induced damage, not all cross links are excised. There is, therefore, cumulative DNA damage leading to mutations, apart from the mutagenesis, overexposure to sunlight depresses the local immune system, and possibly decreasing immune surveillance for new tumor cells, it also develops as a result of Basal-Cell Nevus Syndrome, or Gorlin Syndrome, which is also characterized by Keratocystic odontogenic tumors of the jaw, ${ }^{(6)}$ palmar or plantar (Sole of the foot) pits, calcification of the falx cerebri (in the center line of the brain) and rib abnormalities.

The cause of the syndrome is a mutation in the PTCHI tumor suppressor gene at chromosome 9q22.3, which inhibits the hedgehog signaling pathway, a mutation in the SMO gene, which is also on the hedgehog pathway, also causes basal-cell carcinoma. Patients present with a shiny, pearly nodule. However, superficial basal-cell cancer can present as a red patch like eczema. Infiltrative or morpheaform basal-cell cancers can present as a skin thickening or scar tissue, making diagnosis difficult without using tactile sensation and a skin biopsy. It is often difficult to visually distinguish basal-cell cancer from acnescar, actinic elastosis, and recent cryodestruction inflammation.

Basal-cell carcinoma is a common skin cancer, but when solar (actinic) Keratoses are also considered, basal cell carcinoma are second in prevalence. Basal cell carcinoma occurs mainly in fair -skinned patients with a family history of this cancer. Sunlight is a factor in about two-thirds of these cancers, therefore, doctors recommend sun screens with at least SPF30. One-third occur in non-subexposed areas; thus, the pathogenesis is more complex that UV exposure as the cause.

The use of a chemotherapeutic agent such as 5-Fluorouracil or Aldara (Imiquimod), can prevent development of skin cancer. It is usually recommended to individuals with extensive sun damage, history of multiple skin cancers, or rudimentary forms of cancer (i.e., solar keratosis). It is often repeated every 2 to 3years to further decrease the risk of skin cancer. 


\section{CASE REPORT}

TREATMENT: The lesion needs to be removed if the biopsy indicates cancer, the type of surgery depends on the size of the tumor, the following methods are employed in the treatment of basal cell carcinoma (BCC). The goal is to get rid of the cancer while leaving a scar as small as possible:

1. Surgery.

2. Radiation therapy.

3. Chemotherapy.

4. Mohs Micrographic Surgery.

1. SURGICAL EXCISION: The surgical excision can be with either frozen section histology or paraffin-embedded fixed-tissue pathology, it is a preferred method for removal of most B.C.C, a dermatoscope can help an experienced surgeon accurately identify the visible tumor that the naked eye cannot see(7) The narrower the free surgical margin (skin removed that is free of visible tumor) the higher the recurrence rate. ${ }^{(8,9)}$ If a $4 \mathrm{~mm}$ free surgical margin is obtained around a small tumor (less than $6 \mathrm{~mm}$ ), the cure rate is very high-95\% or better(10,11) however, for cosmetic reasons, many doctors take only very small surgical margins $1-2 \mathrm{~mm},{ }^{(12)}$ a weakness with standard surgical excision is the high recurrence rate of basal-cell cancers of the face, especially around eyelids, (13) nose and facial structure.(14) On the face, or on recurrent basal-cell cancer after previous surgery, special surgical margin controlled processing (CCPDMA - Compete circumferential peripheral and deep margin assessment(15) using frozen section histology (Mohs surgery is one of the methods) is required. Surgery for the middle ear basal cell carcinoma, the type and amount of surgery depends on where the cancer is in the ear, surgery may involve having some are all of the following removed.

1. The Ear Canal.

2. Part or all the Temporal Bone (Temporal bone resection).

3. The Middle ear.

4. The Inner ear.

2. RADIATION THERAPY: Radiotherapy can be delivered either as external beam radiotherapy or as brachytherapy (Internal radiotherapy). Although radiotherapy is generally used in older patients who are not candidates for surgery, it is also used in cases where surgical excision will be disfiguring or difficult to reconstruct (Especially on the tip of the nose, and the nostril rims). Radiotherapy can also be useful if surgical excision has been done incompletely or if the pathology report following surgery suggests a high risk of recurrence. Cure rate can be as high as $95 \%$ for small tumor, or as low as $80 \%$ for large tumors. Usually, recurrent tumors after radiation are treated with surgery.

3. CHEMOTHERAPY: Uses Anti -Cancer (cytotoxic) drugs to destroy cancer cells, some superficial cancers respond to local therapy with 5-fluorouracil, a chemotherapy agent. Topical treatment with 5\% Imiquimod cream, with five applications per week for six weeks has a reported 70-90\% success rate at reducing, even removing, the BCC. Chemotherapy often follows Mohs surgery to eliminate the residual superficial basal-cell carcinoma after the invasive portion is removed, some advocate the use of imiquimod prior to mohs surgery to remove the superficial component of the cancer.(16) 


\section{CASE REPORT}

4. MOHS SURGERY: Dr Frederic Mohs developed this technique of removing skin cancer using a microscopy. Mohs micrographic surgery is an outpatient procedure in which the tumor is surgically excised and then immediately examined under microscope. It is a form of pathology processing called CCPDMA (complete circumferential peripheral and deep margin assessment.(17) The base and edges are microscopically examined to verify sufficient margins before the surgical repair of the site, if the margins are insufficient more is removed from the patient until the margins are sufficient, it is also used for SCC, however the cure rate is not as high as mohs surgery for basal cell carcinoma. The following indications for Mohs surgery, the cure rate is more than $98 \%$.

1. Large Tumor.

2. Tumor in a sensitive area of the body.

3. Tumor is there for a long time.

4. Recurrent cases.

CONCLUSION: Basal cell carcinoma in the ear presents as an aggressive Phenotype in the majority of cases for both men and women and it occurs much more frequently in men, knowledge of this information can help to guide physicians and ensure that these tumors are adequately biopsied and treated. We describe a case of Basal cell carcinoma in middle ear in a 45 year old female, presented as aural polyp.

\section{REFERENCES:}

1. Basal cell carcinoma (http://WWW.nlm.nih.gov/medlineplus/ency/article/000824.htm).

2. Wong CS, Strange RC. Lear JT (October 2003). "Basal cell carcinoma”. (https://www.ncbi.nlm.nih.gov/pmc/articles/PMC214105). BMJ 327 (7418):794-8.

3. Freedberg, et al. (2003). Fitzpatrick's Dermatalogy in General Medicine. (6 $6^{\text {th }}$ ed). Mc.Graw-Hill. ISBN 0-07-138076-0.

4. James, William D.; Berger, Timothy G.; et al. (2006). Andrews' Disease of the skin: clinical dermatology. Saunders Elsevier. ISBN 0-7216-2921-0.

5. Laffay L, Depaepe L, d'Hombres A, Balme B, Thomas L, De Bari B (2012). "Histological features and treatment approach of trichoblastic carcinoms: from a case report to a review of the literature." Tumori 98(2): 46e-49e. doi:10.1700/1088.11948.

6. Case 3-2008. An 80-year-old woman with cutaneous basal-cell carcinoma and cysts of the jaws". N Engl J Med 358 (4): 393-401. Doi: 10. 1056/NEJMcpc0707893.

7. Scalvenzi M, Lembo S, Francia MG, Balato A (October 2008). "Dermoscopic patterns of superficial basal cell carcinoma”. Int. J. Dermatol. 47 (10): 1015-8. doi:10.1111/j.1365-4632.2008.03731.

8. Cuellar F, Vilalta A, Puig S, Palou J, Zaballos P, Malvehy J (September 2008). "Dermoscopy of early recurrent basal cell carcinoma". Arch Dermatol 144 (9):1254. doi:10.1001/archderm.144.9.1254.

9. Maloney Me, et al. (1999). Surgical Dermatopathology, Cambridge, MA: Blackwell publlishers.p.110.ISBN 0-86542-299-0. 
10. Silverman MK, Kopf AW, Bart RS, Grin CM, Levenstein MS (June 1992). "Recurrence rates of treated basal cell carcinomas. Part 3: Surgical excision”. J Dermatol Surg Oncol 18(6): 471-6 doi:10.1111/j.1524-4725.1992 tb03307.

11. Skin Malignancies, Squamous cell carcinoma. (http:// emedicine. medscape.com/article/1295550-overview) at eMedicien.

12. Griffiths RW, Suvarna SK, Stone J (2007). "Basal cell carcinoma histological clearance margins: an analysis of 1539 conventionally excised tumours. Wider still and deeper?". J Plast Reconstr Aesthet surg 60 (1):41- Doi: 10.1016/j. bjps.2006.06.009.

13. Sigurdsson H, Arnarsson BA (August 1998). "Basal cell carcinoma of the eyelid. Risk of recurrence according to adequacy of surgical margins". Acta Opthalmol Scand 76 (4): 477-80. doi: 10.1034/j.1600-0420. 1998. 760416.

14. Farhi D, Dupin N, Palangie A, Carlotti A, Avril MF (October 2007). "Incomplete excision of basal cell carcinoma: rate and associated factors among 362 consecutive cases” Dermatol Surg 33 (10):1207-14 doi:10.1111/j.1524-4725.2007.33255.x.

15. Dhingra N, Gajdasty A, Neal JW, Mukherjee AN, Lane CM (June 2007). "Confident complete excision of lid-margin BCCs using a marginal strip: an alternative to Mohs' surgery". $\mathrm{Br} \mathrm{J}$ Opthalmol 91 (6):794-6. Doi: 10.1136 /bjo. 2006.109892.

16. Butler DF, Parekh PK, Lenis A (January 209). "Imiquimod 5\% cream as adjunctive therapy for primary, solitary, nodular nasal basal-cell carcinomas before Mohs micrographic surgery:a randomized, double blind, vehicle-controlled study". Dermatol Surg 35.

17. Minton TJ (August 2008). "Contemporary Mohs surgery applications" Current Opinion in Otolaryngology \& Head and Neck Surgery 16 (4):376-80. doi:10.1097/M00.0b013e3283079.

\section{AUTHORS:}

1. T. Shankar

2. S. Ramakrishna

3. E. Yugandhar

4. Juveria Majeed

\section{PARTICULARS OF CONTRIBUTORS:}

1. Professor, Department of ENT, Osmania Medical College,

2. Professor and HOD, Department of ENT, Osmania Medical College.

3. Resident, Department of ENT, Osmania Medical College.

4. Resident, Department of ENT, Osmania Medial College.

Date of Submission: 30/01/2015.

Date of Peer Review: 31/01/2015.

Date of Acceptance: 17/02/2015.

Date of Publishing: 26/02/2015.

FINANCIAL OR OTHER

COMPETING INTERESTS: None 